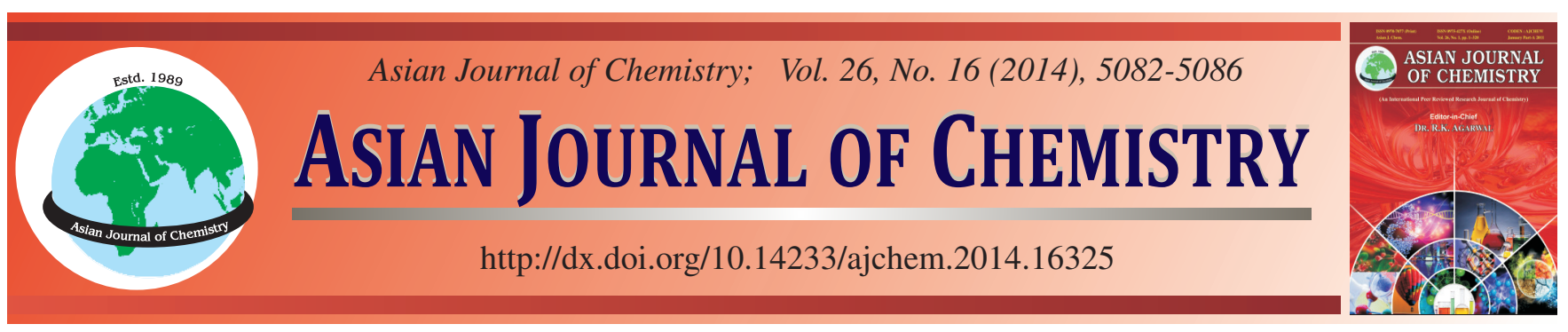

\title{
Simultaneous Quantitative Determination of Four Kinds of Parabens in Soy Sauce by UPLC-MS/MS
}

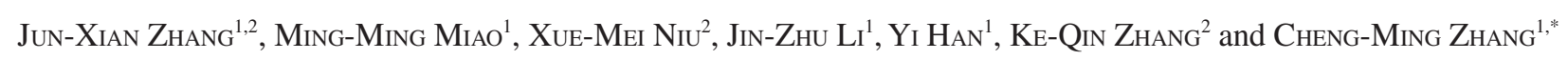

${ }^{1}$ Key Laboratory of Tobacco Chemistry of Yunnan Province, Yunnan Academy of Tobacco Science, Kunming 650106, P.R. China ${ }^{2}$ Laboratory for Conservation and Utilization of Bio-Resources \& Key Laboratory for Microbial Resources of the Ministry of Education, Yunnan University, Kunming 650091, P.R. China

*Corresponding author: Tel: +86 18787146807; E-mail: 969657214@163.com

\begin{abstract}
A new method for simultaneous determination and quantitation of four kinds of parabens (methyl paraben, ethyl paraben, propyl paraben and butyl paraben) in soy sauce has been developed by using solid-phase extraction (SPE) combined with ultra performance liquid chromatography-tandem mass spectrometry (UPLC-MS/MS). Two sample type (blended and brewed) were used for method evaluation. Recoveries were mostly higher than $90 \%$, method detection limits ranged from 0.55 to $2.08 \mathrm{ng} \mathrm{mL}^{-1}$ and method quantification limits were included between 1.84-6.92 $\mathrm{ng} \mathrm{mL}^{-1}$. Due to matrix effect, quantitation was performed by referring to a matrix matched calibration curve, for each soy sauce typology. This method was also applied to commercial soy sauce samples, with good results.
\end{abstract}

Keywords: Parabens, Soy sauce, Solid-phase extraction, UPLC-MS/MS.

\section{INTRODUCTION}

Esters of $p$-hydroxy benzoic acid (Fig. 1), commonly known as parabens, include methyl paraben (MP), ethyl paraben (EP), propyl paraben (PP) and butyl paraben (BP). They are widely used as preservatives for food, cosmetics and pharmaceuticals in restricted concentration levels because of their relatively low toxicity profile, non-volatility, neutrality and broad-spectrum antimicrobial activity ${ }^{1-3}$. The antimicrobial activity of parabens increases with an increase in the length of the alkyl chain of the ester group ${ }^{1}$, but in practice, shorter esters are commonly employed because of their higher solubility in water ${ }^{4}$. Combinations of two or more parabens are often used together since they have synergistic effects ${ }^{4}$.<smiles>[R]OC(=O)c1ccc(O)cc1</smiles>

Methyl paraben $\mathrm{R}=-\mathrm{CH}_{3}$ Ethyl paraben $\mathrm{R}=-\mathrm{CH}_{2} \mathrm{CH}_{3}$ Eropyl paraben $\mathrm{R}=-\mathrm{CH}_{2} \mathrm{CH}_{2} \mathrm{CH}_{3}$ Butyl paraben $\mathrm{R}=-\mathrm{CH}_{2} \mathrm{CH}_{2} \mathrm{CH}_{2} \mathrm{CH}_{3}$

Fig. 1. Chemical structures of paraben compounds
Recently, parabens in cosmetic products have received more attention, because the elevated amounts of parabens in topical products have been shown to induce allergic contact dermatitis ${ }^{1}$. Routledge et al. ${ }^{5}$ described the oestrogenic activity of parabens and they have been recently reported to have oestrogenic activity in yeast cells and animal models $\mathrm{s}^{1,6-8}$. Oestrogen is a major etiological factor in the growth and development of the majority of human breast cancers. It has been reported that the mean concentration of parabens in 20 human breast tumors was found to be $20.6 \pm 4.2 \mathrm{ng} \mathrm{g}^{-1}$ tissue $^{6}$. In addition, butyl paraben even has an epigenetic effect on spermatogenic germ cells in the adult rat testis ${ }^{8}$. The above studies indicated that even though long-term, low-dose consumption maybe has side effects on humans and wildlife. Therefore, it is necessary to establish rapid and effective methods for the determination of parabens in different kinds of food to ensure food safety and human health.

In the last few years several methods have been developed for the determination of parabens, mainly using high-performance liquid chromatography (HPLC) ${ }^{9,10}$, gas chromatography $(\mathrm{GC})^{11}$, capillary electrophoresis ${ }^{12-15}$, thin-layer chromatography $^{6}$ and microemulsion electrokinetic chromatography ${ }^{16}$. A few methods have been published based on the use of LC$\mathrm{MS} / \mathrm{MS}^{16,17}$ and GC-MS ${ }^{18-21}$. 
In this study, we have developed a sensitive, dependable and simple method, based on solid-phase extraction (SPE) of the samples and reversed-phase UPLC-MS/MS to simultaneously determine four parabens including methyl paraben, ethyl paraben, propyl paraben and butyl paraben in soy sauce, which is often used in cooking as a condiment. Two typologies of soy sauce were spiked with the parabens and then analyzed, to optimize the entire method and determine accuracy (recovery), precision, method detection limit (MDL), method quantification limit (MQL) and linearity range. The method was finally tested on commercial soy sauce samples.

\section{EXPERIMENTAL}

HPLC-grade methanol were purchased from TEDIA (Ohio, USA). Standards, including methyl paraben, ethyl paraben, propyl paraben, butyl paraben, were purchased from AccuStandard Inc (New Haven, CT). All other chemicals were analytical-reagent grade. Deionized water was obtained from a Milli-Q water system (Millipore, Bedford, MA, USA) and was used throughout the study.

For solid phase extraction, Sep-pak Vac 6 cc (1 g) C18 Cartridges (Waters, Milford, MA, USA) were used.

Standard stock solutions of each paraben were prepared at $100 \mu \mathrm{g} \mathrm{mL} \mathrm{m}^{-1}$ level in methanol and stored at $4{ }^{\circ} \mathrm{C}$ in glass vials.

Extraction procedure: Test samples including blended soy sauce and brewed soy sauce were purchased from local supermarkets in Kunming, P.R. China and stored at $4{ }^{\circ} \mathrm{C}$.

$2 \mathrm{~mL}$ sample was diluted to $100 \mathrm{~mL}$ with water and then $5 \mathrm{~mL}$ of the diluted sample was loaded into an C18 cartridge activated prior to use by passing through $5 \mathrm{~mL}$ of methanol followed by $5 \mathrm{~mL}$ water. The cartridge was then sequentially rinsed with $3 \mathrm{~mL} 90 \%$ aqueous methanol. The eluate was made up to $5 \mathrm{~mL}$ with $90 \%$ aqueous methanol before filtration $(0.22 \mu \mathrm{m}$ microporous membrane) into injection bottles. The final extract was analyzed by UPLC-MS/MS.

UPLC-MS/MS instrumentation and conditions: The liquid chromatography tandem mass spectrometry system was comprised of an API $4000 \mathrm{MS} / \mathrm{MS}$ System equipped with an electrospray ionization (ESI) probe and a syringe pump (AB Sciex, Foster City, CA, USA) and an Ultra Performance LC system was equipped with a binary pump and an autosampler (Waters, Milford, MA, USA). The system was connected by PEEK tubing (1/16 in. o.d. $\times 0.01$ in. i.d.). Data was acquired and processed using AB Sciex Analyst software (version 1.5.1). Samples $(5 \mu \mathrm{L})$ of the final extracts were separated on an ACQUITY UPLC BEH C18 column $(2.1 \times 100 \mathrm{~mm} ; 1.7 \mu \mathrm{m}$ particles) at a flow rate of $0.4 \mathrm{~mL} \mathrm{~min}^{-1}$ and eluted with a linear binary gradient of $0.05 \%$ formic acid in water (A) and methanol (B) (Table-1). The temperature of the analytical column was maintained at $40{ }^{\circ} \mathrm{C}$.
TABLE-1

MOBILE PHASE GRADIENT PROGRAM OF UPLC-MS/MS

(A: $0.05 \%$ FORMIC ACID IN WATER AND B: METHANOL)

Time (min) $\quad$ Methanol (\%) $\quad 0.05 \%$ Formic acid in water $(\%)$

\begin{tabular}{lll}
\hline 0 & 10 & 90 \\
3 & 90 & 10 \\
4 & 90 & 10 \\
5 & 10 & 90 \\
6 & 10 & 90 \\
\hline
\end{tabular}

Detection of analytes were operated in the negative ion mode. Optimization of the operation conditions, infusing diluted stock solutions of each analyte into the mass spectrometer were as follows: source temperature $600{ }^{\circ} \mathrm{C}$, curtain gas $30 \mathrm{psi}$ ( $83 \mathrm{kPa}$ of max. $99.5 \%$ nitrogen), ion source gas 1 (nebulizer gas) $60 \mathrm{psi}$ (414 kPa of nitrogen), ion source gas 2 (auxiliary gas) of $60 \mathrm{psi}$ (276 kPa of nitrogen), spray voltage $4.5 \mathrm{kV}$. Other MS parameters are shown in Table-2.

Method validation: A standard calibration line was constructed by analyzing mix solutions at six concentration levels in the ranges of 10-500 $\mathrm{ng} \mathrm{mL}^{-1}$. Two different matrix matched calibration curves were also performed by spiking the extracts of blended and brewed soy sauce, respectively, in order to cover two main typologies of soy sauce. Each curve was constructed by addition of appropriate volumes of the standard mix working solution at blank soy sauce sample extracts in order to have the same concentration levels of the standard working solution. The paraben peak area versus paraben concentration in soy sauce samples were plotted to get the calibration curves.

Signal suppression or enhancement on ESI-MS/MS response due to matrix effect was evaluated, for each analyte, by comparing the slope of the standard calibration curve with the slope of the matrix matched calibration curve.

Accuracy was evaluated in terms of percentage of recovery on the two soy sauce typologies earlier described. For recovery studies blank soy sauces were spiked prior to the extraction step. A volumn-measured aliquot of the sample was added of a small and suitable volume of working solutions of the analytes. After a few minutes extraction was carried out, as previously described.

For each analyte, five replicates of three levels of concentration, corresponding to 20,100 and $500 \mathrm{ng} \mathrm{mL}^{-1}$, were investigated. The averaged recovery, for each soy sauce typology, the relative standard deviations (RSD) and the relative errors (RE) were calculated.

To calculate the method detection limit and method quantification limit of each analyte, seven repliacates of blank soy sauce sample extracts spiked with an appropriate volume of the standard mix working solution in order to have the same concentration level of the lowest level of the calibration curve were analyzed and the method detection limit and method

\begin{tabular}{ccccc}
\multicolumn{5}{c}{ TABLE-2 } \\
OPTIMIZED MS PARAMETERS OF PARABENS \\
\hline Analyte & Precursor ion $(\mathrm{m} / \mathrm{z})$ & Product ion $(\mathrm{m} / \mathrm{z})$ & Declustering potential $(\mathrm{U} / \mathrm{V})$ & Collision energy $(\mathrm{U} / \mathrm{eV})$ \\
\hline Methyl paraben & $151.6[\mathrm{M}-\mathrm{H}]^{-}$ & $92.0^{*} / 136.0$ & $55 / 55$ & $29 / 19$ \\
Ethyl paraben & $165.5[\mathrm{M}-\mathrm{H}]^{-}$ & $92.0^{*} / 136.0$ & $51 / 55$ & $30 / 21$ \\
Propyl paraben & $179.8[\mathrm{M}-\mathrm{H}]^{-}$ & $92.0^{*} / 136.0$ & $62 / 61$ & $31 / 23$ \\
Butyl paraben & $193.8[\mathrm{M}-\mathrm{H}]^{-}$ & $92.0 * / 136.0$ & $55 / 55$ & $29 / 22$ \\
\hline *Quantitative ion. & & & &
\end{tabular}


quantification limit were expressed as $3 \times \mathrm{SD}$ and $10 \times \mathrm{SD}$, respectively.

\section{RESULTS AND DISCUSSION}

Extraction: Matrix effect can be reduced with dilution and samples were diluted 50-fold in this research for sufficient recoveries of four kinds of parabens were obtained with that.

For solid phase extraction clean-up, the effect of various concentrations of eluent solution on the recoveries of the analytes were investigated. Soy sauce matrix spiked with parabens was used and quantitation was calculated by using the standard calibration curve. Fig. 2, it can be seen that the recoveries of parabens in $90 \%$ methanol solution was high, especially the recovery of butyl paraben. So $90 \%$ methanol was selected as the eluent for the clean-up of parabens.

Optimization of chromatographic and MS/MS conditions: Analytes were mass-selected and fragmented. For each compound two ion pairs were chosen for acquisition in multiple reaction monitoring (MRM) mode. Precursor ions of methyl paraben, ethyl paraben, propyl paraben and butyl paraben were $m / z$ 151.6 [M-H] ${ }^{-}, m / z 165.5\left[^{-\mathrm{M}-\mathrm{H}]}\right]^{-}, \mathrm{m} / \mathrm{z}, 179.8$ $[\mathrm{M}-\mathrm{H}]^{-}$and $m / z 193.8[\mathrm{M}-\mathrm{H}]^{-}$. Product ions were $m / z 136.0$ $\left[\mathrm{M}-\mathrm{CH}_{3}\right]^{-}$and $\mathrm{m} / \mathrm{z} 92.0\left[\mathrm{M}-\mathrm{CH}_{3} \mathrm{CO}_{2}\right]^{-}$for methyl paraben, $\mathrm{m} / \mathrm{z}$ $136.0\left[\mathrm{M}-\mathrm{C}_{2} \mathrm{H}_{5}\right]^{-}$and $\mathrm{m} / z$ 92.0 $\left[\mathrm{M}-\mathrm{C}_{2} \mathrm{H}_{5} \mathrm{CO}_{2}\right]^{--}$for ethyl paraben, $m / z 136.0\left[\mathrm{M}-\mathrm{C}_{3} \mathrm{H}_{7}\right]^{-}$and $m / z 92.0\left[\mathrm{M}-\mathrm{C}_{3} \mathrm{H}_{7} \mathrm{CO}_{2}\right]^{-}$

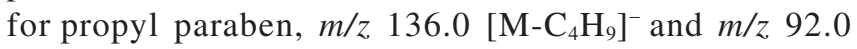
$\left[\mathrm{M}-\mathrm{C}_{4} \mathrm{H}_{9} \mathrm{CO}_{2}\right]^{-}$for butyl paraben, respectively. Tuning parameters are summarized in Table-2.

UPLC separation was performed using reversed phase chromatography and satisfactory separation was obtained with methanol and formic acid in water as mobile phases. Typical UPLC-ESI-MS/MS chromatogram of four parabens was shown in Fig. 3. The retention time of methyl paraben, ethyl paraben, propyl paraben and butyl paraben are 3.03, 3.37, 3.66 and $3.90 \mathrm{~min}$, respectively.

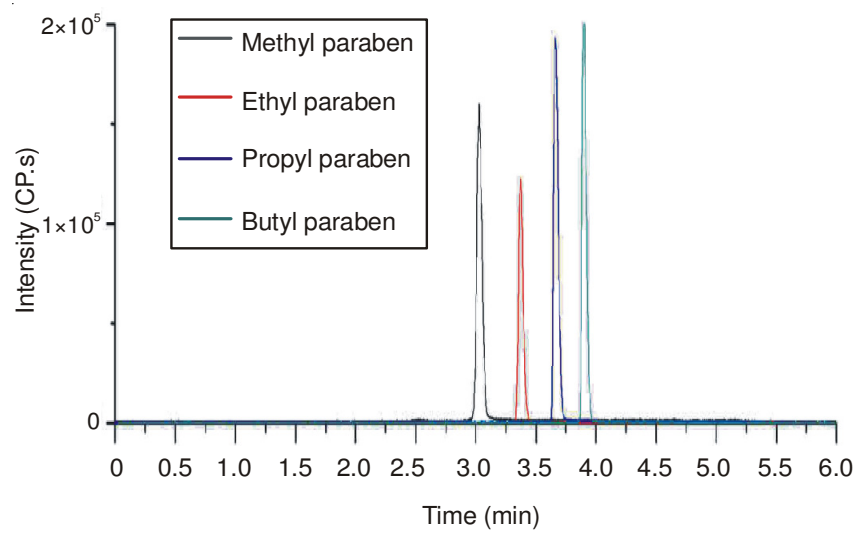

Fig. 3. Typical extracted ion chromatogram (XIC) of four prarabens

Method validation: As illustrated above, linear calibration curves were obtained both by standard calibration and by matrix matched procedures. The linearity ranges of all the analytes, in the two different soy sauce typologies, were evaluated. For each analyte the calibration curves and their linear regression analysis are shown in Table-3. All calibration curves showed good linear regression ( $\mathrm{R} \geq 0.9990)$ within linear range.

The matrix effect was calculated and shown in Table- 3 . The average ratio between slopes $\left(b_{\text {matrix }} / b_{\text {standard }}\right)$ is strongly dependent on soy sauce typology and parabens. For blended soy sauce it was less than or equal to 1, showing signal suppression. For brewed soy it was more than 1, showing signal enhancement. Due to these obvious differences between standard and matrix matched calibration, we chose to carry

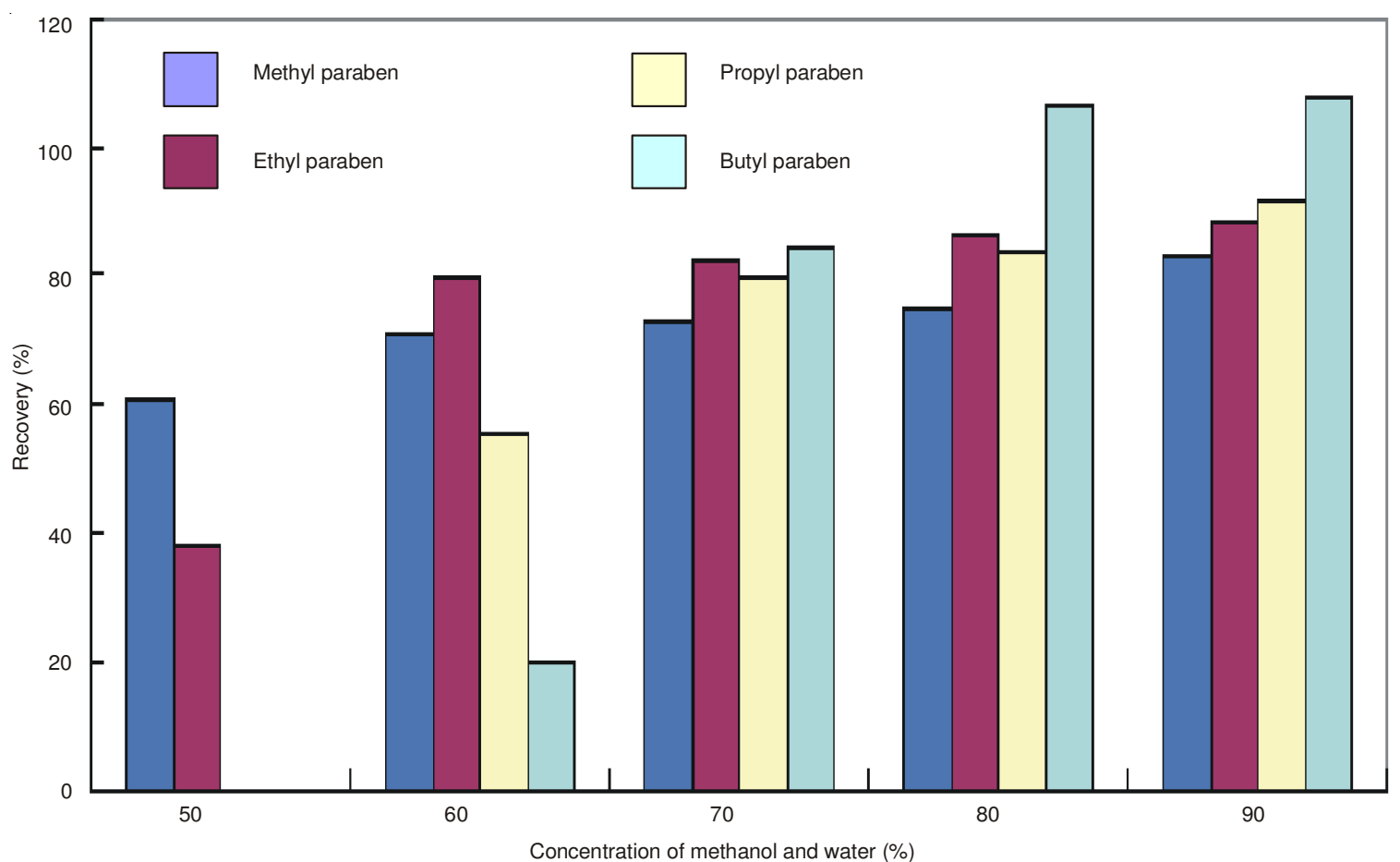

Fig. 2. Recovery of parabens (methyl paraben, ethyl paraben, propyl paraben and butyl paraben) using dfferent concentrations of methanol (from $50 \%$ water to $90 \%$ methanol) as washing solution 


\begin{tabular}{cccc}
\hline \multicolumn{4}{c}{ TABLE-5 } \\
METHOD DETECTION LIMIT (MDL) AND \\
METHOD QUANTITATION LIMIT (MQL) \\
\hline \multirow{2}{*}{ Paraben } & $\begin{array}{c}\text { Soy sauce } \\
\text { typology }\end{array}$ & $\begin{array}{c}\text { MDL } \\
\left(\mathrm{ng} \mathrm{mL}^{-1}\right)^{\mathrm{a}}\end{array}$ & $\begin{array}{c}\text { MQL } \\
\left(\mathrm{ng} \mathrm{mL}^{-1}\right)^{\mathrm{b}}\end{array}$ \\
& Blended & 0.70 & 2.34 \\
\multirow{2}{*}{ Methyl paraben } & Brewed & 0.55 & 1.84 \\
\hline \multirow{2}{*}{ Ethyl paraben } & Blended & 1.43 & 4.77 \\
& Brewed & 0.69 & 2.31 \\
\hline \multirow{2}{*}{ Propyl paraben } & Blended & 1.24 & 4.13 \\
& Brewed & 1.19 & 3.95 \\
\hline \multirow{2}{*}{ Butyl paraben } & Blended & 2.08 & 6.92 \\
& Brewed & 1.60 & 5.34 \\
\hline
\end{tabular}

${ }^{a}$ Method detection limit was calculated as $3 \times$ SD of 7 replicates of blank soy sauce sample extracts spiked with standard mix working solution to have the concentration of $10 \mathrm{ng} \mathrm{mL}^{-1}$ of each paraben. ${ }^{b}$ Method detection limit was calculated as $10 \times$ SD of 7 replicates of blank soy sauce sample extracts spiked with standard mix working solution to have the concentration of $10 \mathrm{ng} \mathrm{mL}^{-1}$ of each paraben.

assure an accurate determination, quantitation was calculated by using the matrix matched calibration curve depending on soy sauce typology. All the four kinds of parabens were not found in those real samples, as it is declared on the label of the samples.

\section{Conclusion}

In this work, combining solid-phase extraction with UPLC-MS/MS, a new method for simultaneous determination and quantitation of four kinds of parabens (methyl paraben, ethyl paraben, propyl paraben and butyl paraben) in soy sauce has been developed by using two different typologies of soy sauce (blended and brewed). A relevant matrix effect in both of the two typologies was observed. By applying the matrix matched calibration curves, the method showed good recoveries of parabens added to soy sauce of two different typologies, always above $83 \%$ and RSDs were less than $8.78 \%$. Method detection limit and method quantification limit were 0.55-2.08 $\mathrm{ng} \mathrm{mL} \mathrm{m}^{-1}$ and 1.84-6.92 $\mathrm{ng} \mathrm{mL}^{-1}$, respectively.

The method was tested against commercial samples, to confirm its reliability, with results in line with their respective labels.

\section{ACKNOWLEDGEMENTS}

This work was supported by Construction of a System of China Tobacco Yunnan Industrial Co., Ltd. for Quality Safety Evaluation of Cigarette Materials (2011JC04).

\section{REFERENCES}

1. R. Golden, J. Gandy and G. Vollmer, Crit. Rev. Toxicol., 35, 435 (2005).

2. C. Charnock and T. Finsrud, J. Clin. Pharm. Ther., 32, 567 (2007).

3. D. Sasseville, Dermatol. Ther, 17, 251 (2004).

4. Q.L. Zhang, M. Lian, L. Liu and H. Cui, Anal. Chim. Acta, 537, 31 (2005).

5. E.J. Routledge, J. Parker and J. Odum, Toxicol. Appl. Pharmacol., 153, 12 (1998).

6. P.D. Darbre, A. Aljarrah, W.R. Miller, N.G. Coldham, M.J. Sauer and G.S. Pope, J. Appl. Toxicol., 24, 5 (2004).

7. J.R. Byford, L.E. Shaw, M.G.B. Drew, G.S. Pope, M.J. Sauer and P.D. Darbre, J. Steroid Biochem., 80, 49 (2002).

8. C.J. Park, W.H. Nah, J.E. Lee, Y.S. Oh and M.C. Gye, Andrologia, 44, 187 (2012).

9. Y.K. Chen, W.S. Kong, L. Wang, Z.Y. Chen, G.Y. Yang and M.M. Miao, Asian J. Chem., 24, 4932 (2012).

10. S. Antakli, R. Kabani and D. Shawa, Asian J. Chem, 25, 1123 (2013).

11. J.L. Lach and J.S. Sawardeker, J. Pharm. Sci., 54, 424 (1965).

12. L. Labat, E. Kummer, P. Dallet and J.P. Dubost, J. Pharm. Biomed. Anal., 23, 763 (2000).

13. A. De Rossi and C. Desiderio, Electrophoresis, 23, 3410 (2002).

14. H. Huang, I. Huang and H. Lin, J. Sep. Sci., 29, 2038 (2006).

15. E. Blanco, M.C. Casais, M.C. Mejuto and R. Cela, Electrophoresis, 29, 3229 (2008).

16. P.E. Mahuzier, K.D. Altria and B.J. Clark, J. Chromatogr. A, 924, 465 (2001).

17. X. Ye, A.M. Bishop, L.L. Needham and A.M. Calafat, Anal. Chim. Acta, 622, 150 (2008).

18. M.C. Pietrogrande and G. Basaglia, TrAC Trends Anal. Chem., 26, 1086 (2007).

19. E. Villaverde-de-Sáa, I. González-Mariño, J.B. Quintana, I. Rodríguez and R. Cela, Anal. Bioanal. Chem., 397, 2559 (2010).

20. R.A., Pérez, B. Albero, E. Miguel and C. Sánchez-Brunete, Anal. Bioanal. Chem., 402, 2347 (2012).

21. Y. Han, X.Y. Jia, X.L. Liu, T. Duan and H.T. Chen, Chromatographia, 72, 351 (2010). 